Proceedings

\title{
Formulation Development of a Patient Friendly Dosage Form for Eye Drug Delivery: Kajal ${ }^{\dagger}$
}

\author{
Sandeep Waghulde, Archana Pawar *, Minal Kadav, Pratiksha Khade, Mohan Kale, \\ Bharat Tekade, Nilesh Gorde and Pravin Naik
}

Konkan Gyanpeeth Rahul Dharkar College of Pharmacy and Research Institute, Karjat, University of Mumbai, 410201 Mumbai, Maharashtra, India

* Correspondence: archupawar03@gmail.com

+ Presented at the 22nd International Electronic Conference on Synthetic Organic Chemistry, 15 November-15 December 2018; Available online: https://sciforum.net/conference/ecsoc-22.

Published: 14 November 2018

\begin{abstract}
Traditionally, kajal is known as kohl or surma and is used as eyeliner. Designing herbal kajal with medicinal plants as a cosmetics product is considered to bea novel, innovative technique. The main advantages of such a product are that it is patient friendly, water resistant, stable, and economical to formulate. Two medicinal plants, viz., Rosa rubiginosa and Triphala, were evaluated for their potential for sustained ocular delivery with the aim of formulating herbal kajal. Standardization of the herbs was performed based on different physiochemical parameters, and the obtained values were within the prescribed limits. On the basis of the selected parameters and its antimicrobial potential, herbal kajal was evaluated in comparison with comparable products.
\end{abstract}

Keywords: kohl; kajal; Rosa rubiginosa; Triphala; herbal kohl

\section{Introduction}

The eyes are an important connection between the outer and inner worlds. In Ayurveda (an Indian system of medicine), pitta dosha stands for the element of fire and light that governs our eyes. Hence, the eyes are very important organs in our body. For care and beautification of the eyes, Vedic science offers several natural, safe, and effective techniques. With the help of Ayurvedic science, several herbs and floras have been used to make Ayurvedic cosmetics that not only beautify the skin but also protect against external effects on the body. In cosmetics, for useful purposes such as moisturizing, whitening, coloring, sunscreens, antioxidants, immunostimulants, cleansing, preservatives, thickeners, etc., plant products are also used. The role of kajal in eye products cannot be ignored, as it is one of those products [1].

Kajal is worn for many reasons, including tradition, beautification, or to ward off the "evil eye". It is a widespread belief that kohl is medically beneficial for the eyes, and wearing kohl is encouraged in the Sunna, which encompasses the traditional behavioral guidelines of the Islamic religion [2]. There are a number of plants which are used for ophthalmic disorders, either aloneorin compound formulations, that can be found in the Ayurvedic system of medicine, as mentioned in ancient Indian books such as Charak Samhita, Sushrut Samhita, Bhav Prakasha, Ras Tarang, Nayan Drastam, and Astanghriday. Various eye disorders and diseases, such as Abhishyand (conjunctivitis), Adhimanth (glaucoma), Timir (cataract), etc., have been described in great detailin Ayurveda. Their etiology and treatments have also been described. The use of various herbal drugs in different dosage forms, such as extracts, arkas (aqueous distillate), kajal (collerium), and fomentation and washing with different extracts, has also been prescribed frequently [3]. Not only the use of animals for laboratory testing but also the materials and ingredients derived from animal sources is an 
concern of area regarding the standards and quality of drugs and cosmetics manufactured and sold in India, which are governed by the Drugs and Cosmetics Act [1].

Hence, for the "natural" products used in various preparations, there is a need for regulation. The best way to create trust and confidence in these products and increase market relevance is through standardization. The consumer as well as the practitioner now seeks assurance from the manufacturer about the quality, safety, and efficacy of products. Thus, earlier recommendations related to cosmetic preparations with herbs for specific conditions may not hold true today unless properly validated [4]. In this study, different extracts of Rosa rubiginosa and Triphala herbs were selected to formulate kajal. Well known in Ayurveda, Triphala is a polyherbal formulation that is a Rasayana drug used in the Indian System of Medicine (ISM) [5]. As described in the Ayurvedic formulary of India, it is a mixture of the dried fruits of Emblica officinalis Gaertn (Euphorbiaceae), Terminalia bellerica Linn (Combertaceae), and Terminalia chebula (Combertaceae) inequal proportions (1:1:1) [6]. The most commonly found polyphenolic compounds in plant extracts are tannins, gallic acid, chebulagic acid, ellagic acid, phenols, and glycosides. Phenolic acids, flavonoids, and tannins are commonly found in Triphala [7]. Triphala is also widely taken for many eye diseases, including the treatment of conjunctivitis, progressive myopia, the early stages of glaucoma, and cataracts, as described by Mahajan et al. Triphala ghrita is given at a dose of $1080 \mathrm{mg}$ to delay the onset and progression of cataracts. The antioxidant activity of gallic acid, ellagic acid, and ascorbic acid may also have anticataract effects [8]. For the cure of constipation, inflammation, and swelling and to ease throat infections, rose water has traditionally been used. However, when used as eye drops, it can help cure eye issues. Herbal preparations that also include rose extracts have been used to prepare eye drops for use on patients suffering from dry eyes, conjunctivitis, and pterygium. Such eye drops are also used by postoperative cataract patients, and a significant improvement in their condition has been noticed. Needless to say, rose water is good for the eyes.

Rose water helps to soothe the eyes, treat skin irritation, prevent cell damage, and lighten dark circles [9]. Formulating medicated kajal for beautification and as a cosmeceutical product to combat eye infections has been thought of as an innovative approach, as kajal's medicinal use is limited and it is mostly used as eye makeup. Considering this, the present study aimed to prepare a contemporary formulation from the preliminary Ayurvedic kajal called soot/lamp black using two herbs, namely, R. rubiginosa and Triphala and to standardize it in terms of identity, physical evaluation, and toxicity.

\section{Materials and Methods}

\subsection{Collection of Plant Materials andProximal Analysis}

The fresh fruits of Triphala, such as amala, baheda, and haritaki, and the flowers of R. rubiginosa were collected. Quantitative standards for the fruits of Triphala and the petals of the R. rubiginosa flower, in terms of moisture content, total ash, acid-insoluble ash, and alcohol- and water-soluble extractive values for both samples, were performed by preliminary macroscopical identification of both the raw plant materials. This was carried out as per the method described by the World Health Organization (WHO) guidelines [10].

\subsection{Preliminary Ayurvedic Formulation of Kajal}

The required quantity of rose petals and the dried powder of Triphala fruits for preparing the extract was acquired.

The extract was hygienically prepared, and an unbleached cloth was soaked in the rose extract and dried in a hot air oven.

The dried cloth piece was used as a wick and was lighted in a mud lamp containing cow ghee.

The black soot was collected in a clean, dry porcelain dish. 
The powder was then mixed with cow ghee to form a paste (i.e., kajal).

\subsection{Contemporary Formulation of Kajal}

The modern kajal (Table 1) was formulated in the same manner as preliminary Ayurvedic kajal,andthe ingredients are given below in Table 1.

Table 1. Quantitative composition of the formulation of kajal.

\begin{tabular}{cc}
\hline Ingredients & Quantity Taken \\
\hline Kajal powder & $10 \mathrm{~g}$ \\
Cow ghee & $15 \mathrm{~g}$ \\
Rose water extract & $0.5 \mathrm{~mL}$ \\
Triphala extract & $0.5 \mathrm{~mL}$ \\
BHA & $12 \mathrm{~g}$ \\
BHT & $12 \mathrm{~g}$ \\
\hline
\end{tabular}

\subsection{Standardization of Ingredients, Processes, and Products}

The standardization of the quality of the ingredients used in theproduct was done by using thin-layer chromatography (TLC). The physiochemical characteristics of the lamp black, plant extracts of two separate herb plants and the kajal powder were determined by the Karl Fischer method (for moisture content), a penetrometer test (the pressure at which the needle penetrates), TLC, and microbial contamination and toxicity studies.

\subsubsection{TLC of Extracts}

Both the R. rubiginosa and Triphala extracts were checked by TLC (Tables 2 and 3) on analytical plates over silica gel. The isolation of the principle components that were present in most effective extracts of the plants and the final products were carried out using TLC. The different polarities of the solvents were prepared, and for better resolution, TLC studies were carried out to select a suitable solvent system [11]. Based on that, $6 \mathrm{~g}$ of the product (prepared from $R$. rubiginosa) was subjected to Soxhlet extraction with water as a solvent. Further, $65 \mathrm{~g}$ of whole-plant Triphala was refluxed with $100 \mathrm{~mL}$ of alcohol for $1 \mathrm{~h}$ and then evaporated in awater bath to reduce the volume. The crude extract was then diluted to a sufficient volume of alcohol.

Finally, the leaf extract of $R$. rubiginosa, lamp black, and kajal products and the alcoholic plant extract of Triphala, lamp black, and kajal products were subjected to TLC using two separate mobile phases, viz., toluene:acetone:formic acid (11:6:1) and toluene:ethyl acetate (95:5) for $R$. rubiginosa and Triphala, respectively. Both of the samples were visualized at 254 and $366 \mathrm{~nm}$, and a band of similar Rf values was identified.

Table 2. Thin-layer chromatography (TLC) for ingredients (water extract, lamp black extract) and product (water kajal extract) of Rosa rubiginosa at different wavelengths.

\begin{tabular}{cccc}
\hline Visualization & Water Extract & Lamp Extract & Kajal Extract \\
\hline $254 \mathrm{~nm}$ & $T_{1}: 0.67\left(R_{\mathrm{f}}\right)$ & $T_{2}: 0.67\left(R_{\mathrm{f}}\right)$ & $T_{4}: 0.09\left(R_{\mathrm{f}}\right)$ \\
$366 \mathrm{~nm}$ & $T_{1}: 0.67\left(R_{\mathrm{f}}\right)$ & $T_{2}: 0.67\left(R_{\mathrm{f}}\right)$ & $T_{4}: 0.09\left(R_{\mathrm{f}}\right)$ \\
\hline
\end{tabular}

$T_{1}, T_{2}, T_{3}$, and $T_{4}$ are the tracks of the respective extracts. 
Table 3. TLC for ingredients (alcoholic extract, lamp black extract) and product (alcoholic kajal extract) of Triphala at different wavelengths.

\begin{tabular}{cccc}
\hline Visualization & Alcoholic Extract & Lamp Extract & Kajal Extract \\
\hline $254 \mathrm{~nm}$ & $T_{1}: 0.58\left(R_{\mathrm{f}}\right)$ & $T_{2:}: 0.60\left(R_{\mathrm{f}}\right)$ & $T_{4}: 0.60\left(R_{\mathrm{f}}\right)$ \\
$366 \mathrm{~nm}$ & $T_{1}: 0.58\left(R_{\mathrm{f}}\right)$ & $T_{2}: 0.60\left(R_{\mathrm{f}}\right)$ & $T_{4}: 0.60\left(R_{\mathrm{f}}\right)$ \\
\hline
\end{tabular}

$T_{1}, T_{2}, T_{3}$, and $T_{4}$ are the tracks of the respective extracts.

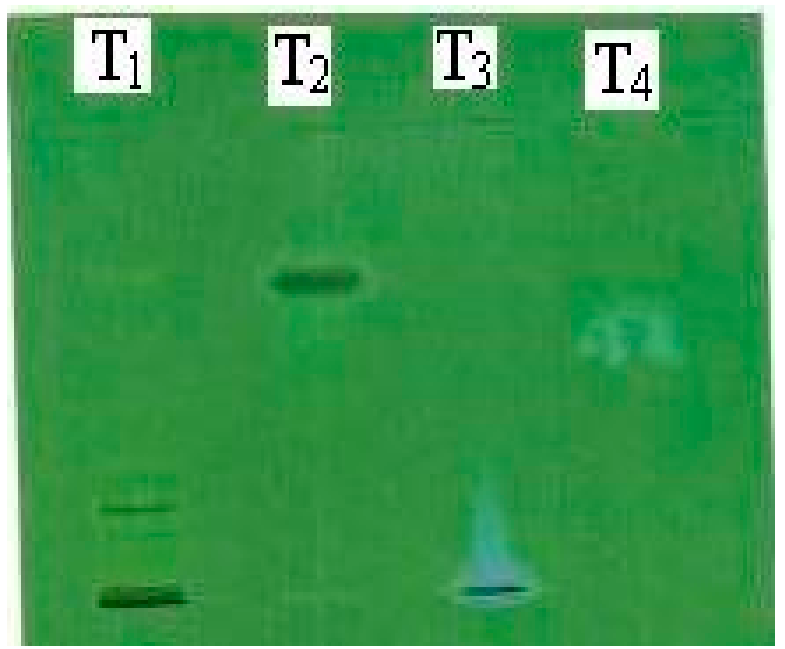

(a)

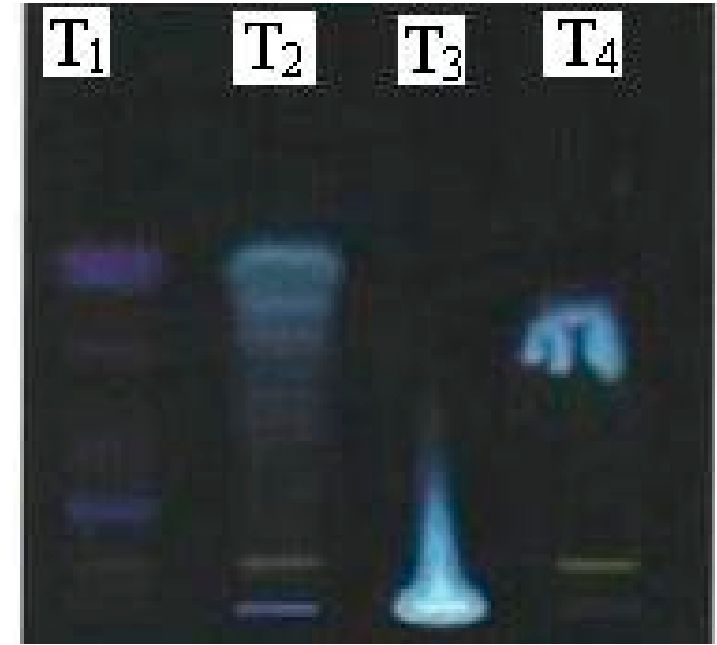

(b)

Figure 1. TLC plates at different wavelengths for R. rubiginosakajal extracts: (a) UV at $254 \mathrm{~nm}$; (b) UV at $366 \mathrm{~nm}$.

\subsubsection{Microbial Contamination}

Microbial tests were performed to check the quality of the kajal products to determine the microbial, total fungal, and Escherichia coli countsby acylindrical plate method. Nutrient agar (for total bacterial count), MacConkey agar (for total E. coli count), and Sabouraud dextrose agar (for fungal and yeast count) were incubated at $37^{\circ} \mathrm{C}$ overnight, $43{ }^{\circ} \mathrm{C}$ overnight, and $25^{\circ} \mathrm{C}$ for 4 days, respectively. Finally, the growth was observed and, by a colony counter, counted in per volume plated, and the results are expressed as CFU/g (colony forming units per gram of the sample).

\subsection{Evaluation of Allergenic Studies on Kajal Products}

Physical Evaluation: The formulated product was of a shiny black color, with a characteristic odor. It was non gritty and smooth in texture with a semisolid consistency.

PH Determination: From a pH meter; read as 7.2

Viscosity Determinations: By using a Brookfield Viscometer.

Evaluation of Base: For acid, saponification, and ester values, vegetable ghee was evaluated as per I.P. 1996.

Acid Value: Acid value $=5.61 \times \mathrm{n} / \mathrm{w}$, where $\mathrm{n}$ is the number of $\mathrm{ML}$ of $0.1 \mathrm{M} \mathrm{KOH}$ required and $\mathrm{w}$ is the weight in grams of the solvent; $\mathrm{n}=0.5$ and $\mathrm{w}=2.0$. Thus, the acid value was $5.61 \times 0.5 / 2=$ 1.4025 .

Saponification Value: Saponification value $=28.05(b-a) / w$, where $w$ is the weight in grams of the substance, $b$ is the blank solution reading, and $a$ is the sample solution reading; $b=21, a=4.6$, and $\mathrm{w}=2.0$ Therefore, the saponification value was $28.05(21-4.6) / 2=230.01$. Theester value equals the saponification value minus the acid value. Thus, ester value was230.01 $-1.4025=228.6075$. 


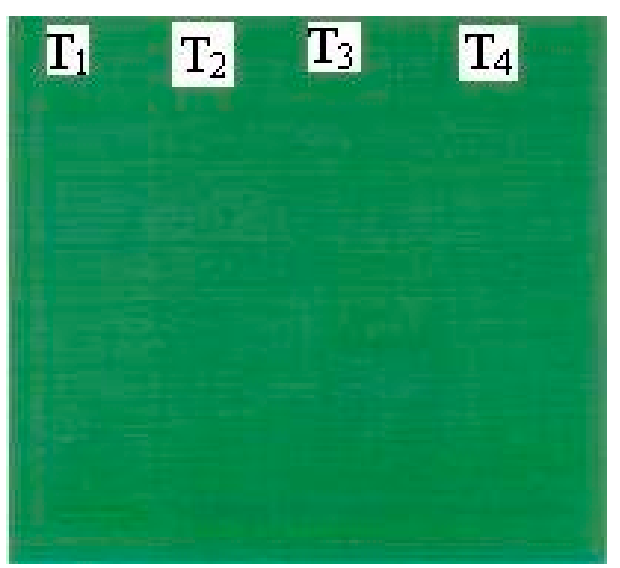

(a)

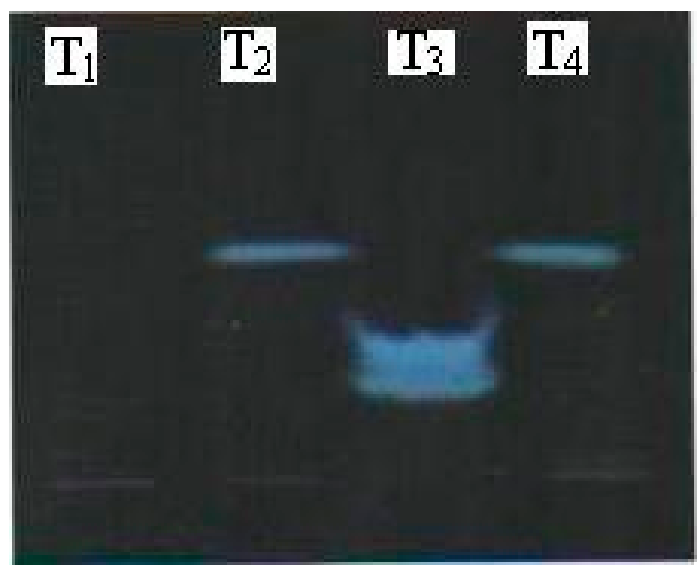

(b)

Figure 2. TLC plates at different wavelengths for Triphala kajal extracts: (a) UV at $254 \mathrm{~nm}$; (b) UV at $366 \mathrm{~nm}$.

\section{Conclusions}

The standardization of Triphala and $R$. rubiginosa plants wascarried out with respect to organoleptic characteristics, and thesame characteristics were found for both asthose reported in the official pharmacopoeia. Similarities in the values for both herbs were revealed by carrying out various proximate parameters. The chromatographic profile of the plant extracts showed that there were compounds present that had similar $R_{f}$ values in both of them when they were identified and separated with different mobile phases. Thereafter, microbial tests showed the absence of microbial loads in both plant products, which demonstrated the safety of the kajal products. Thus, the formulated herbal kajal is safe and can be used as an herbal cosmetic product.

\section{References}

1. Srikanth, T.; Hussen, S.S.; Anand, A.; Vasantharaju, S.G. Sandeep. Der Pharm. Lett. 2011, 3, 334-341.

2. Parry, C.; Eaton, J. Kohl: A lead-hazardous eye makeup from the third world to the first world. Environ. Health Perspect. 1991, 94, 121-123.

3. Dutt, S.A. Hindi Commentary, Susruta Samhita; Chaukhamha Publications: New Delhi, India, 2009; Volume II, pp. 1-108.

4. Stone, B.C. The Flora of Guam. A manual for the identification of the vascular plants of the Island. Micronesica 1970, 6, 1-659.

5. Govindarajan, R.; Vijaykumar, M.; Pushpangadan, P. Antioxidant approach to disease management and the role of Rasayan herbs of Ayurveda. J. Ethnopharmacol. 2005, 99, 165-178.

6. The Ayurvedic Formulary of India; Part-II; Department of Indian System of Medicine and Homeopathy: New Delhi, India, 2002.

7. Singh, D.P.; Govindarajan, R.; Rawat, A.K.S. High Performance Liquid Chromatography as a tool for the Chemical Standardisation of Triphala-An Ayurvedic Formulation. Phytochem. Anal. 2008, 19, 164-168.

8. Mahajan, K.N.; Singhal, A.K.; Vadnere, G.P. Investigation on anti-cataract activity of Triphalaghrita. E-J. Chem. 2011, 8, 1438-1443.

9. 10 Benefits of Rose Water for Skin and 16 Ways to Use It. Available online: https://www.stylecraze.com/ articles/benefits-of-rosewater-for-eyes/\#gref (accessed on October 2018).

10. WHO. Quality Control Methods for Medicinal Plants Materials; WHO: Geneva, Switzerland, 1998; p. 1115

11. Harborne, J.B. Phytochemical Methods: A Guide to Modern Techniques of Plants Analysis; Chapman and Hall: London, UK, 1998. 